\title{
A malandragem em perspectiva crítica
}

Thiago Moraes Fernandes Cruz ${ }^{1}$

RESUMO:

O presente trabalho analisará a sequência crítica de três ensaios relacionados ao romance "Memórias de um sargento de milícias" de Manuel Antônio de Almeida: "Dialética da malandragem" de Antonio Candido; "Pressupostos, salvo engano, de 'Dialética da malandragem"” de Roberto Schwarz; e "Espírito rixoso: para uma reinterpretação das Memórias de um Sargento de milícias” de Edu Teruki.

\begin{abstract}
:
This paper will examine the critical sequence of three essays related to the novel "Memoirs of a militia sergeant" by Manuel Antônio de Almeida: "Dialectics of rascality" by Antonio Candido "Assumptions, if am not mistaken, of 'Dialectics of rascality" by Roberto Schwarz, and "Quarrelsome spirit: for a reinterpretation of Memoirs of a militia sergeant" by Edu Teruki.
\end{abstract}

PALAVRAS-CHAVE: Dialética da malandragem; Antonio Candido; Roberto Schwarz; Edu Teruki;

KEYWORDS: Dialectics of rascality; Antonio Candido; Roberto Schwarz; Edu Teruki;

\section{Entre dois polos}

Publicado inicialmente em 1970 na revista do IEB, o ensaio A Dialética da Malandragem de Antonio Candido tornou-se um marco da crítica nacional, ao renovar a leitura do romance "Memórias de um sargento de milícias". Na medida em que o ensaio de Candido toma como ponto de partida a fortuna crítica existente até então sobre o livro de Manuel Antônio de Almeida e também gera outros dois textos que o retomam dialeticamente, ele torna-se um elo de um desenvolvimento crítico de fôlego e longo alcance, formando uma incomum e proveitosa sequência no pensamento nacional.

Duas visões críticas postas como antitéticas motivam as reflexões do Autor: a visão naturalista de José Veríssimo, que elogia a obra em razão da visão descritiva mediante a qual enfoca a sociedade fluminense no período joanino, antecipando-lhe, assim, traços supostamente realistas; e a de Mário de Andrade que vê as Memórias como uma continuadora do romance picaresco do Século de ouro espanhol, tomando-a, portanto, não uma antecipadora de um movimento, mas como uma continuadora atrasada.

Candido tem como ponto de partida essas duas críticas ao postular que o romance de Manuel Antonio de Almeida não é um precursor do realismo, segundo José Veríssimo, nem um filho temporão da novela picaresca, como queria Mario de Andrade. Em relação ao primeiro, aponta a falha imperdoável do romance se tomado como

\footnotetext{
${ }^{1}$ Mestrando no Programa de Estudos Comparados de Literaturas de Língua Portuguesa, do DLCV/USP.
} 
romance documental, já que praticamente exclui do enredo as classes de mando e os escravos, classes fundamentais na caracterização social da época; enquanto que em uma análise mais objetiva, as Memórias apresentariam mais diferenças do que proximidades com a narrativa picaresca, como a diferença de foco narrativo e suas implicações estéticas.

O crítico resolve a dualidade entre as duas visões antitéticas, sintetizando-as na figura do malandro. Isso porque o tom burlesco das tramoias praticadas pelas personagens do livro, correspondente ao tipo de humor satírico do Brasil joanino, e a proximidade com a figura do pícaro pelo viés universalista e a-histórico do trickster estão presentes na constituição do tipo malandro. Além desta visão folclórica do “espertalhão da lenda" e daquele humor datado do período regencial, a figura do malandro explicará um importante movimento das personagens entre o polo da ordem e desordem, que no plano extraliterário será a redução estrutural de um movimento análogo presente na sociedade brasileira da época.

De acordo com Roberto Schwarz, a figura do malandro é analisada por Candido sob três aspectos:

(...) O herói Leonardo será visto (...) como malandro (uma figura historicamente original, que sintetiza: a) uma dimensão folclórica e pré-moderna - o trickster; b) um clima cômico datado - a produção satírica do período regencial; c) uma intuição profunda da sociedade brasileira (SCHWARZ, 2006, p. 131).

Ou, em outras palavras:

(...) a personagem central é caracterizada como malandro. Essa figura enfeixa uma dimensão folclórica (o espertalhão da lenda), uma dimensão de época (o estilo satírico da Regência), e um movimento em que está transposto um dinamismo histórico de alcance - como se verá - nacional (as idas e vindas entre os hemisférios da ordem e da desordem sociais) (SCHWARZ, 2006, p. 138).

O malandro sintetiza, portanto, uma dimensão universalista e outra histórica, além de um movimento estrutural que organiza tanto o ritmo da obra como o da sociedade. Esse movimento - estrutura comum tanto às Memórias quanto à sociedade brasileira da época joanina - será chamado por Candido "dialética da ordem e desordem" e será o argumento central do seu ensaio.

Partindo da ideia de que Manuel Antônio de Almeida praticamente exclui do romance a classe trabalhadora (os escravos) e a classe de mando (os proprietários), Candido ressalta que o enredo é construído basicamente por personagens representantes de uma faixa intermediária da sociedade brasileira, os homens livres e pobres. Esses 
homens, que não pertencem à elite e nem são a força produtiva da sociedade, vivem um dilema: não são assalariados - já que o trabalho é escravo - mas necessitam dos bens de consumo inseridos na lógica do Capital.

$\mathrm{O}$ atraso da estrutura convivendo funcionalmente com a moderna superestrutura obriga os homens livres e pobres direta ou indiretamente à vida parasitária em relação a algum proprietário, latifundiário, mediada pela relação de favor.

Segundo Schwarz:

Nem proprietários nem proletários, seu acesso à vida social e a seus bens depende materialmente do favor, indireto ou direto de um grande. O agregado é a sua caricatura. O favor é, portanto, o mecanismo através do qual se reproduz uma das grandes classes da sociedade, envolvendo também outra, a dos que têm (SCHWARZ, 2008, p. 16).

A dialética da ordem e desordem é, portanto, um achado crítico notável na medida em que estabelece uma perspectiva de análise inovadora: considera a primazia da estrutura da obra para a crítica literária sem, no entanto, ser estruturalista, já que a relaciona a uma estrutura análoga da sociedade; ou, de forma complementar, fundamenta a análise da obra com a matéria sócio-histórica, sem reduzir aquela em um banco de dados ilustrativo desta, distanciando-se da sociologia da literatura.

\section{A positividade indesejável}

Depois de apontar a originalidade do ensaio de Antonio Candido, Roberto Schwartz verifica que o Autor - que durante boa parte do ensaio faz uma crítica materialista - cede a uma análise culturalista da malandragem, lendo-a como um ethos brasileiro fora de sua especificidade histórica.

\footnotetext{
Somando, digamos os argumentos ora puxam em direção do histórico, ora em direção ao ethos cultural (...) Assim, a dialética da ordem e desordem é construída inicialmente enquanto experiência e perspectiva de um setor social, num quadro de antagonismo de classes historicamente determinado. Ao passo que noutro momento ela é o modo de ser brasileiro, isto é, um traço cultural através do qual nos comparamos a outros países e que em circunstâncias favoráveis pode nos ajudar" (CANDIDO, 2004, p.44).
}

Roberto Schwarz nota que após intuir o livre trânsito entre ordem e desordem pela perspectiva histórica, Antonio Candido opõe a esse movimento histórico-social bem definido uma outra interpretação das Memórias. De caráter popular e universalizante, essa outra leitura da obra revela uma positividade desproblematizada, 
indesejável à crítica materialista já que dilui a especificidade histórico-social no caldo generalizante da cultura:

Manuel Antônio ficou à vontade e aberto para as inspirações de ritmo popular. Essa costela, que é pré-crítica, mas que, pelo fato de reduzir tudo à amplitude da 'natureza humana', se torna afinal mais desmistificadora do que a intenção quase militante de um Alencar, mareada pelo estilo de classe (...) a linguagem de Manuel Antônio desvinculada da moda, torna amplos, significativos e exemplares os detalhes da realidade presente, porque os mergulha no fluido do populário, que tende a matar lugar e tempo (...) Trata-se de uma libertação, que funciona como se a neutralidade moral correspondesse a uma neutralidade social, misturando as pretensões das ideologias no balaio da irreverência popularesca (CANDIDO, 2004, p. 44).

Antonio Candido, em certo momento do seu ensaio, imita o tom geral das Memórias ao equiparar a já citada dimensão folclórica e histórica da malandragem. Essa mímese dá ao ensaio um ritmo particular brilhante, cujo preço é a suspensão da análise histórica que vinha sendo realizada até então. A dialética entre ordem e desordem fantasia-se como uma possibilidade privilegiada de combate ao mundo puritano burguês ao invés de única alternativa dos homens livres e pobres.

Roberto Schwarz é quem vê essa atitude de equiparar a análise histórica com a ahistórica como uma interrupção no movimento dialético de Candido:

Antônio Candido traz à frente outra vez a dimensão folclórica que tratara antes, e faz da tensão e contaminação das duas a peculiaridade da obra: a universalidade incaracterística e conformista da sabedoria popular evapora muito do realismo do livro, o que se compensa de outro lado, pois o realismo dá concreção social aos padrões muito genéricos do folclore. (...) Para nosso argumento, veja-se que esta forma (...) em que se equilibram o ritmo histórico e o a-histórico, não será interpretada historicamente por sua vez. A pergunta pelo sentido, no caso, de uma cunhagem folclórica do mundo moderno não é feita. Neste ponto, a dialética histórica não prossegue. Por quê? (...) a história aqui não é o chão prioritário de tudo (...) A exemplo do romance, o ensaio equipara história e sabedoria popular. Em consequência, a composição do primeiro vale também para a conceituação do segundo, que a imita e passa a participar de seu realismo 'brandamente fabuloso', na feliz expressão do crítico (SCHWARZ, 2006, p. 150).

A leitura feita por Candido interrompe o desenvolvimento dialético na medida em que equipara as visões folclórica e histórica do livro, colocando-as como complementares, equivalentes. Ou seja, a crítica abre mão da sua aspiração histórica ao não questionar a visão universalizante projetada sobre uma sociedade moderna, a sociedade brasileira do período joanino. 
Ao retomar "A Dialética da Malandragem" sob a perspectiva crítica, apontando no movimento final do texto de Antonio Candido o afrouxamento da leitura histórica em detrimento da folclórica, Roberto Schwarz dá sequência crítica ao estudo da malandragem, importante linha de força brasileira.

A linhagem do malandro lida sob o ângulo folclórico universaliza essa figura, que, se aproximando do tipo trapaceiro presente em toda mitologia, se afasta da especificidade da matéria histórica brasileira. A perspectiva folclórica, então, ao elidir as arestas que tornam o malandro uma figura originalmente brasileira, suprime-lhe também os seus conflitos históricos, construindo a aura positiva - porque desproblematizada - em torno da malandragem.

Essa positivação da malandragem do texto de Candido, ao ser retomada pela leitura negativa de Roberto Schwarz, inicia um diálogo crítico cujo movimento dialético conduz à transformação de uma visão culturalista e positiva da malandragem para uma visão negativa e histórica, na qual a malandragem deixa de ser um traço cultural isolado e se torna uma importante chave interpretativa da sociedade brasileira a partir do século XIX.

\section{O lado sombrio da malandragem}

No ensaio "Nacional por subtração" (SCHWARZ, 2006, p. 29), Roberto Schwarz aponta que um problema da vida intelectual brasileira é o desinteresse pela produção das gerações passadas. Ocupada na constante atualização em relação ao que é produzido nos países de primeiro mundo, a inteligência brasileira paga um alto preço por esse descaso com o conhecimento já produzido: a descontinuidade da reflexão crítica dos problemas internos. Ao ignorar a produção da geração anterior - na busca dessa atualização guiada pelo influxo externo - cria-se um entrave no adensamento de questões pertinentes à realidade brasileira, impedindo uma sequência crítica do pensamento nacional.

Alguns escritores seguiram na contramão dessa tendência, ao tomarem a produção anterior como ponto de partida de suas reflexões:

Machado de Assis, Mário de Andrade e, hoje, Antonio Candido (...). A nenhum deles faltou informação nem abertura para a atualidade. Entretanto, todos souberam retomar criticamente e em larga escala o trabalho dos seus predecessores, entendido não como peso morto, mas como elemento dinâmico e irresolvido, subjacente às contradições contemporâneas (SCHWARZ, 2006, p.31). 
Como foi dito anteriormente, "A dialética da malandragem" não só foi uma tese que dialogou com a fortuna crítica existente até então sobre as Memórias, como também motivou sua antítese em "Pressupostos, salvo engano, de 'Dialética da Malandragem"”. Ao dialogar com fortuna crítica produzida até então, o ensaio "A Dialética da Malandragem" funciona como um convite para que ele próprio fosse também revisitado criticamente, integrando, assim, uma notável sequência da inteligência brasileira.

Edu Teruki, ao retomar a leitura d' "A dialética da malandragem" feita por Roberto Schwartz, em "O espírito rixoso: para uma reinterpretação das Memórias de um Sargento de milícias" retoma o movimento dialético entre ordem e desordem proposto por Candido, subordinando-o a outro movimento: ao das rixas. Depois de parafrasear uma série episódios do romance de Manuel Antônio de Almeida onde o espírito rixoso da desavença pessoal aparece como responsável pelo encadeamento do enredo, conclui:

(...) a tendência para a discórdia pessoal não é uma simples excentricidade ou idiossincrasia restrita a um ou a outro personagem, mas sim um padrão de comportamento que se manifesta em praticamente todas as relações interpessoais figuradas nas Memórias, bem como na perspectiva do narrador. Nesse sentido, pode-se dizer que o espírito rixoso se generaliza no romance e apresenta caráter estrutural (OTSUKA, 2007, p. 112).

A rixa entendida como uma rivalidade fútil, cuja finalidade extingue-se em si mesma, é oposta à vingança premeditada e articulada para a obtenção de um objetivo real. Antonio Candido, na análise do romance "O conde de Monte Cristo" (CANDIDO, 2006, p.15), associa a vingança pessoal do protagonista ao individualismo, e esse à conduta burguesa. A vingança de Edmundo Dantés é, portanto, símbolo de uma nação que já vivia a plenitude do sistema capitalista e, por consequência, a autonomia do sujeito, realidade bem diferente do Rio joanino.

Comparando a vingança objetiva empreendida com uma finalidade específica com a rixa, percebemos que estas se movem em função de si mesmas, ou seja, o espírito rixoso ao contrário da vingança - empreendimento de caráter propriamente burguês, movidas por um objetivo exterior - esgota-se em si mesma, gerando outras rixas, autonomizando esse mecanismo. Forma de disputa entre os homens livres e pobres, a rixa tinha como função rebaixar o oponente e não gratificar o vencedor da contenda com algo real. De fato, o objetivo do espírito rixoso é uma espécie de compensação imaginária: 
(...) os personagens (...) lançam mão dos expedientes da malandragem, estabelecendo conflitos rixosos em busca do prestígio que não alcançam por via do favor (...) De certo modo, na falta de proteção de um poderoso, a rixa apresenta-se para os pobres como o único lugar em que é possível afirmar uma supremacia (um pouco na realidade e muito na imaginação) (OTSUKA, 2007, p. 121).

O autor conclui que em um mercado onde a mão de obra era escrava e as poucas possibilidades de trabalho dependiam do mecanismo do favor, deixavam os homens livres e pobres em uma situação funesta, em que a rixa era usada como mecanismo de compensação imaginária frente à remota possibilidade de trabalho.

O encadeamento entre os três estudos citados sobre as Memórias de um sargento de Milícias revela um movimento dialético de fôlego da crítica brasileira, construindo uma sólida continuidade em torno da malandragem, uma linha de força tão cara à formação nacional. Esse movimento estrutura-se a partir da positivação e negativação da figura do malandro. O texto de Candido ao sugerir a flexível dialética entre ordem e desordem como uma alternativa em relação à rigidez do mundo puritano, eleva-a a possível modelo ao invés de defeito. O problema desse modelo é que sua positividade foi construída a partir da desproblematização histórica da figura do malandro, ou seja, a positivação do malandro paga o preço de uma abordagem culturalista, que encerra a discussão em si mesma. Segundo Edu Teruki:

(...) tal visão parece destacar no romance a representação da malandragem entendida somente como um traço cultural do brasileiro em geral, e não tanto a figuração da malandragem enquanto comportamento historicamente enraizado no quadro específico das relações entre as classes na sociedade brasileira oitocentista (...) Entendida exclusivamente como traço cultural brasileiro, a malandragem tende a ser desvinculada do quadro determinado da organização econômico-social. Desse modo, contudo, a relação entre as Memórias e a sociedade brasileira, tal como apresentada por Candido, fica atenuada ( ou talvez mesmo neutralizada). Isso porque a relação entre obra e a sociedade passa a restringir-se à simples correspondência entre a malandragem literariamente figurada no romance e o comportamento malandro existente na realidade, sem que, no entanto, a própria malandragem real seja entendida em seus fundamentos histórico-sociais (apenas se constata a sua existência no plano da realidade, como um fato auto-evidente que parece não exigir outra explicação para além do impalpável ethos nacional) (OTSUKA, 2007, p. 107).

Ao interpretar as Memórias, Edu Teruki investiga a origem sócio-histórica da malandragem modificando, assim, a interpretação culturalista que Antonio Candido lhe confere no capítulo "Mundo sem culpa". Essa mudança de perspectiva da malandragem corresponde a duas visões distintas, entendidas no plano ideológico, respectivamente, 
como positiva e negativa. O malandro enquanto importante chave de interpretação nacional encontra na crítica literária, a partir de um recorte preciso que é o das Memórias, uma perspectiva histórica e outra, positivada, culturalista.

Referências bibliográficas

ALMEIDA, Manuel Antônio. Memórias de um Sargento de Milícias. São Paulo: Martins Fontes, 2005.

CANDIDO, Antonio. O discurso e a cidade. 3.ed. São Paulo: Duas Cidades, 2004.

CANDIDO, Antonio. Tese e Antítese. 5.ed. São Paulo: Duas Cidades, 2006.

SCHWARZ, Roberto. Que horas são? 2.ed. São Paulo: Companhia das Letras, 2006.

SCHWARZ, Roberto. Ao vencedor as batatas. São Paulo: Ed. 34, 2008.

OTSUKA, Edu Teruki. "Espírito rixoso: para uma reinterpretação das Memórias de um Sargento de milícias”. In: Revista do IEB, São Paulo: 44: 105-124, fev. 2007. 